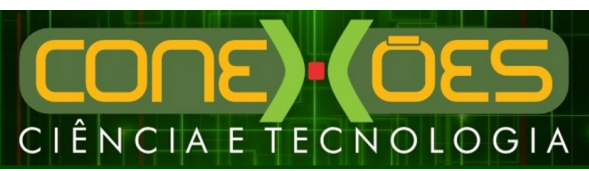

\title{
RESÍDUOS DA CONSTRUÇÃO CIVIL: O GERENCIAMENTO EM UMA OBRA RESIDENCIAL DE GRANDE PORTE EM FORTALEZA-CE
}

\author{
Nirlania Diógenes Leite ${ }^{1}$, Gemmelle Oliveira SAntos $^{1}$ \\ ${ }^{1}$ Instituto Federal do Ceará (IFCE) \\ <nirlania.dl@hotmail.com><gemmelle@ifce.edu.br>
}

DOI: 10.21439/conexoes.v12i3.1238

\begin{abstract}
Resumo. O objetivo dessa pesquisa foi caracterizar o processo de gerenciamento dos resíduos da construção civil em uma obra residencial de grande porte no município de Fortaleza-CE. A obra, ainda em construção, terá $28.291,57 \mathrm{~m}^{2}$ de área construída, sendo 02 torres residenciais, área de lazer completa e 252 apartamentos. Foram realizadas 12 visitas ao canteiro de obras durante um ano e quatro meses para verificar a rotina de gerenciamento dos resíduos. Nessas ocasiões foram realizados registros fotográficos e entrevistas com os responsáveis pelo cumprimento do plano de gerenciamento. Durante a instalação das fundações foram gerados $4,2 \mathrm{~m}^{3}$ de resíduos; na fase de construção das estruturas foram gerados $575,4 \mathrm{~m}^{3}$ de resíduos; e na terceira fase (revestimento das fachadas e acabamento interno) foram gerados $1.292,6 \mathrm{~m}^{3}$ de resíduos, totalizando uma geração de aproximadamente 1.872,20 $\mathrm{m}^{3}$ de resíduos. Quanto à tipologia dos resíduos observou-se que houve a retirada de 363 caçambas estacionárias do local, sendo $743,4 \mathrm{~m}^{3}$ (40\%) de resíduos Classe A, 482,8 $\mathrm{m}^{3}$ (26\%) de madeira (Classe B), $315 \mathrm{~m}^{3}$ (17\%) de gesso (Classe B) e $331 \mathrm{~m}^{3}$ (17\%) de resíduos de todas as classes (misturado). Quanto ao destino final, a Usina de Reciclagem de Resíduos (USIR) recebeu 100\% dos resíduos Classe A, 36,6\% dos resíduos Classe B e 11,4\% dos resíduos Classe C; a empresa Ceará Pallets recebeu 15,6\% dos resíduos Classe B e o Aterro Sanitário Metropolitano Oeste de Caucaia (ASMOC) recebeu 47,8\% de resíduos Classe B e $88,6 \%$ de resíduos Classe C. Salienta-se que parte dos resíduos Classe B (especificamente a madeira) foram selecionados para sua reutilização no próprio canteiro de obras. A pesquisa permitiu observar que o gerenciamento dos resíduos gerados no canteiro de obras caracteriza-se como satisfatório, visto que há um controle interno da quantidade e tipologia do que foi gerado, além de informações sobre o transportador e a destinação final desses resíduos.
\end{abstract}

Palavras-chaves: Resíduos da construção civil. gerenciamento de resíduos.

\section{MANAGEMENT OF CIVIL CONSTRUCTION WASTE IN A LARGE RESIDENTIAL CONSTRUCTION SITE IN FORTALEZA, CEARÁ, BRAZIL}

\begin{abstract}
The purpose of this study was to characterize the construction waste management process in a large residential project in the city of Fortaleza, state of Ceará, Brazil. The project, which is still under construction, will have a built area of 28,291.57 $\mathrm{m}^{2}$ and will be composed of 02 residential towers with 252 apartments and a complete leisure area. 12 visits to the construction site were made during a period of 16 months to check the waste management routine. In such occasions, photographs were taken and those responsible for compliance with the waste management plan were interviewed. During the placement of the foundations $4.2 \mathrm{~m}^{3}$ of waste was generated; another $575.4 \mathrm{~m}^{3}$ in the structure construction phase; and in the third phase (facade cladding and internal finish) generated $1,292.6 \mathrm{~m}^{3}$ of waste, adding up to a grand total of approximately $1,872.20 \mathrm{~m}^{3}$. As for the type of waste, we found that 363 stationary dumpers were removed from the site with $743.4(40 \%)$ of Class A waste, $482.8 \mathrm{~m}^{3}(26 \%)$ of wooden waste (Class B), $315 \mathrm{~m}^{3}(17 \%)$ of gypsum (Class B) and $331 \mathrm{~m}^{3}(17 \%)$ of waste of all classes (mixed). Regarding the final destination, the Waste Recycling Plant received $100 \%$ of the Class A waste, $36.6 \%$ of the Class B waste, and $11.4 \%$ of the Class C waste. Ceará Pallets, a private company, received $15.6 \%$ of the Class B waste, and the West Caucaia Metropolitan Landfill (ASMOC) received $47.8 \%$ of the Class B and $88.6 \%$ of the Class C waste. It is important to say that part of Class B waste (especially wood) were selected to reuse in the construction site. The research allowed to observe that the management of waste in the construction site was satisfactory, since there is an inner control of quantity and typology of it, as well as information about the carrier company and the waste final destination.
\end{abstract}

Keywords: Civil construction waste. waste management. 


\section{INTRODUÇÃO}

Um importante desafio a ser superado pelas construtoras diz respeito ao gerenciamento adequado dos seus resíduos. Segundo Cunha Júnior (2006), o setor é responsável pela geração de mais da metade dos resíduos sólidos urbanos. Conforme o Ministério do Meio Ambiente - MMA (2010), para cada tonelada de lixo domiciliar são geradas até duas toneladas de resíduos da construção.

O volume de resíduos varia de acordo com a área construída. Conforme Pinto (1999), a taxa de geração pode ser de $150 \mathrm{Kg} / \mathrm{m}^{2}$. Publicações da Associação Brasileira das Empresas de Limpeza Pública e Resíduos Especiais - ABRELPE (2011) e do Instituto de Pesquisa Econômica Aplicada - IPEA (2012) apontam que na região Nordeste a média de coleta é estimada em 17.995 toneladas/dia.

Os descuidos com esses resíduos ocasionam danos ao ambiente (por exemplo, aterramento de recursos hídricos, mudança na paisagem) e ao bem-estar da própria sociedade, além do fato da ausência de gerenciamento adequado representar um desperdício de materiais que ainda possuem valor agregado (madeira, ferro, plástico etc) e esgotar a vida útil dos locais de recebimento.

A Resolução 307 do Conselho Nacional de Meio Ambiente - CONAMA, de 05 de julho de 2002, proíbe a disposição dos resíduos de construção em áreas não licenciadas e a CONAMA 448/2012 proíbe a disposição em aterros de resíduos sólidos urbanos, ou seja, cabe aos geradores não gerar e, secundariamente, reduzir, reutilizar, reciclar, tratar e dispor adequadamente os rejeitos.

Conforme a Política Nacional de Resíduos Sólidos (Lei 12.305/2010) o gerenciamento dos resíduos em uma obra deve seguir o plano elaborado pelo interessado e aprovado junto aos órgãos competentes. Esse plano deve conter todos os procedimentos necessários ao manejo (segregação, acondicionamento, transporte interno, armazenamento, transporte externo, tratamento e destino final) dos resíduos da construção.

$\mathrm{Na}$ literatura, existem informações e dados sobre os resíduos da construção civil gerados em diversas cidades do Brasil (SILVA, 2007; GONÇALVES, 2011, SINDUSCON-SP, 2005), mas pouco se sabe sobre a quantidade, tipologia e o gerenciamento no município de Fortaleza-CE.

Na tentativa de contribuir para a redução do déficit de dados sobre os resíduos da construção civil em Fortaleza é que foi realizada essa pesquisa. Durante 1 ano e 4 meses uma obra residencial de 28.291,57 $\mathrm{m}^{2}$ foi acompanhada. Em 12 visitas ao canteiro de obras, todas as etapas do manejo dos resíduos foram monito- radas. Espera-se que os resultados aqui apresentados sirvam para auxiliar estudos posteriores sobre o tema.

O objetivo da pesquisa foi caracterizar o processo de gerenciamento dos resíduos da construção civil em uma obra residencial de grande porte no município de Fortaleza-CE.

\section{METODOLOGIA}

\subsection{2 .1 Classificação da pesquisa}

\section{- Quanto à natureza}

Essa pesquisa pode ser classificada como aplicada, pois seus resultados auxiliam na solução de problemas específicos, ou seja, na gestão e no gerenciamento dos resíduos da construção civil em Fortaleza-CE. Segundo Silva e Menezes (2005) a pesquisa aplicada tem como objetivo a geração de conhecimentos para aplicação prática, sendo dirigidos à solução de problemas específicos; envolvendo interesses locais.

\section{- Quanto aos objetivos}

Essa pesquisa pode ser classificada como exploratória, pois através das entrevistas com os responsáveis pela obra e revisão bibliográfica foi possível compreender a temática dos Resíduos da Construção Civil (RCC) em um canteiro de obras, tendo assim uma visão panorâmica sobre o assunto. Para Marconi e Lakatos (2010) a pesquisa exploratória tem como finalidades o desenvolvimento de hipóteses, facilitar a familiaridade do pesquisador com o ambiente, fato ou fenômeno possibilitando a realização de pesquisas futuras mais precisas, ou ainda viabilizar o entendimento de conceitos.

\section{- Quanto aos procedimentos}

Nessa pesquisa utilizou-se do procedimento de pesquisa documental ao tratar dados que ainda não haviam recebido tratamento analítico, ou seja, baseou-se em fontes primárias. Para Marconi e Lakatos (2010) a pesquisa documental tem como característica a fonte dos dados estar limitada a documentos, escritos ou não, instituindo as denominadas fontes primárias.

\section{- Quanto aos meios de investigação}

A pesquisa utilizou o estudo de caso como meio de investigação, pois houve o acompanhamento de uma obra em particular, sendo um caso dentre vários. Segundo Severino (2007) estudo de caso é o tipo de pesquisa que se aplica ao estudo de uma situação particular, que tem relevância sobre eventos similares, onde os dados devem ser coletados e registrados com rigor e sendo trabalhados mediante análise minuciosa.

\section{- Quanto à abordagem}

Nessa pesquisa foi utilizada uma abordagem quantitativa, onde os dados obtidos foram colocados em planilhas, quantificados e analisados. Silva e Mene- 
zes (2005) afirmam que a pesquisa quantitativa considera que tudo pode ser quantificável, ou seja, podem ser transformados em números opiniões e informações podendo assim serem classificadas e analisadas. Fazendose necessário a utilização de recursos e/ou de técnicas estatísticas.

\subsection{Etapas da pesquisa}

O estudo foi desenvolvido em cinco etapas, a saber: Etapa 1: Revisão de literatura;

Nesta etapa foram realizadas buscas e leituras de arquivos virtuais e impressos sobre o tema principal da pesquisa: resíduos da construção civil. Essa fase teve como principal objetivo aumentar a compreensão sobre o assunto, e o material consultado (artigos, monografias, dissertações, teses, leis, decretos, normas, manuais etc) permitiu construir uma base inicial de saberes e conhecimentos.

Etapa 2: Escolha da empresa, visitas ao canteiro de obras e informações sobre a obra;

Primeiramente entrou-se em contato com a construtora para que fosse autorizado o estudo da obra. Durante a pesquisa foram realizadas 12 visitas ao canteiro de obras, com registros fotográficos e entrevistas com os responsáveis pelo gerenciamento dos resíduos; sendo utilizado também um Diário de Campo. Foram realizadas entrevistas não estruturadas (com engenheiros, técnicos em segurança do trabalho e também com o responsável pelo almoxarifado) na busca de informações sobre o comportamento dos operários quanto ao manejo dos resíduos.

A obra objeto de estudo terá área total construída de 28.291,57 $\mathrm{m}^{2}$, é residencial e composta por duas torres com 23 pavimentos (incluindo o térreo e o mezanino). Está localizada entre a Av. Dr. Theberge e Av. Olavo Bilac, no município de Fortaleza-CE.

A primeira fase da construção foi a instalação das fundações da obra por meio de estacas, que durou dois meses (agosto e setembro de 2015), durante essa etapa foram gerados $4,2 \mathrm{~m}^{3}$ de resíduos.

A segunda fase da construção foi a etapa de instalação das estruturas, com início em outubro de 2015 e término em junho de 2016, onde foram gerados 575,4 m de resíduos. Nesta fase desenvolvem-se diversas peças como: pilares, vigas, vergas, lajes e o seu escoramento, tendo como principais materiais: areia, cimento, brita, (ou concreto pronto), madeira/compensado para formas e aço para ferragens. Quanto ao concreto, devem ser obedecidos os critérios de dosagem, preparo e aplicação específica para cada peça estrutural e caso não sejam obedecidas às normas e recomendações, o índice provável de geração de resíduo pode aumentar.
A terceira fase teve início em julho de 2016 e abrange a etapa de revestimento das fachadas e acabamento interno, com geração de $1.065,8 \mathrm{~m}$ de resíduos. Nesta fase são colocados os pisos, forros, louças, metais sanitários, esquadrias etc. Entre os serviços relativos a essa fase têm-se a passagem da fiação e finalização das instalações elétricas, retoques de azulejos e pisos, colocação de armários, vidros e a pintura.

\section{Etapa 3: Tratamento dos dados e informações;}

Esta etapa envolveu o tratamento dos dados e informações obtidas sobre os resíduos gerados na obra, através da análise de planilhas, do Manifesto de Transporte de Resíduos (MTR) e do Controle de Transporte de Resíduos (CTR) que continham o tipo de resíduo, seu volume e o local para onde foi destinado.

\section{Etapa 4: Discussão dos dados e informações;}

Nesta etapa foram discutidos os resultados simultaneamente com nova visita à literatura.

\section{Etapa 5: Apresentação dos dados e informações;}

Nesta etapa foi realizada uma apresentação na construtora sobre dados e informações obtidos com a pesquisa.

\section{RESULTADOS E DISCUSSÃO}

Na obra estudada, a maior geração de resíduos ocorreu na fase de acabamento, concordando com a pesquisa realizada em São Carlos-SP por Marque Neto e Schalch (2010) e contrariando o pensamento de Dantas (2011), que afirma que na fase de estrutura e alvenaria são observados os maiores volumes de resíduos da construção civil, essa divergência pode ter ocorrido devido a amostra de Dantas ser maior, totalizando 11 construções, além de que o autor analisou obras que estavam em reforma e obras demolidas, esses fatores também influenciam na geração de resíduos.

Valporto, Azevedo e Azevedo (2016), ao analisarem 3 obras, também apontaram a fase de estrutura como a maior geradora de resíduos, principalmente a madeira, sendo considerada o material de maior desperdício. Couto, Naves e Fraga (2016) destacam que o RCC gerado no processo produtivo tem características e composições variáveis, devido à diversidade de materiais e tecnologias utilizadas no processo de construção, bem como em função da etapa ou fase de andamento da obra.

Observou-se que ao longo do processo construtivo houve aumento na geração de resíduos. O Quadro 1 a foi elaborado a partir do tratamento dos dados existentes nas fichas de controle dos resíduos preenchidas pela transportadora contratada sob supervisão de um funcionário da construtora. 
RESÍDUOS DA CONSTRUÇÃO CIVIL: O GERENCIAMENTO EM UMA OBRA RESIDENCIAL DE GRANDE PORTE EM FORTALEZA-CE

Quadro 1: Estimativas do volume de resíduos gerados na obra em 2015/2016

\begin{tabular}{|c|c|c|c|c|}
\hline Competência & $\mathbf{N}^{0}$ de Retiradas & Volume (m3) & Resíduo & Classe do Resíduo \\
\hline set/15 & 1 & 4,2 & \multirow{3}{*}{ Madeira } & \multirow{3}{*}{ B } \\
\hline out/15 & 4 & 4,2 & & \\
\hline \multirow{2}{*}{ nov/15 } & 3 & 4,2 & & \\
\hline & 1 & 4,2 & \multirow{2}{*}{\multicolumn{2}{|c|}{ Classe A }} \\
\hline \multirow{2}{*}{$\mathrm{dez} / 15$} & 3 & 4,2 & & \\
\hline & 1 & 4,2 & Madeira & $\bar{B}$ \\
\hline \multirow{2}{*}{$\mathrm{jan} / 16$} & 4 & 4,2 & Misturado & $\mathrm{C}$ \\
\hline & 8 & 4,2 & \multirow{2}{*}{\multicolumn{2}{|c|}{ Classe A }} \\
\hline \multirow{2}{*}{$\mathrm{fev} / 16$} & 8 & 4,2 & & \\
\hline & 1 & 4,2 & Madeira & \multirow{2}{*}{ B } \\
\hline \multirow{3}{*}{$\operatorname{mar} / 16$} & 1 & 4,2 & Gesso & \\
\hline & 15 & 4,2 & \multicolumn{2}{|r|}{ Classe A } \\
\hline & 1 & 4,2 & Misturado & $\mathrm{C}$ \\
\hline \multirow{4}{*}{$a b r / 16$} & 1 & 4,2 & Gesso & \multirow{2}{*}{ B } \\
\hline & 8 & 4,2 & Madeira & \\
\hline & 7 & 4,2 & Misturado & $\mathrm{C}$ \\
\hline & 9 & 4,2 & \multirow{2}{*}{\multicolumn{2}{|c|}{ Classe A }} \\
\hline \multirow{3}{*}{ mai/16 } & 24 & 4,2 & & \\
\hline & 3 & 4,2 & Madeira & $\mathrm{B}$ \\
\hline & 7 & 4,2 & \multirow{2}{*}{ Misturado } & \multirow{2}{*}{$\mathrm{C}$} \\
\hline \multirow{4}{*}{ jun/16 } & 5 & 4,2 & & \\
\hline & 9 & 4,2 & Madeira & \multirow{2}{*}{ B } \\
\hline & 2 & 4,2 & Gesso & \\
\hline & 12 & 4,2 & \multirow{2}{*}{\multicolumn{2}{|c|}{ Classe A }} \\
\hline \multirow{5}{*}{ jul/16 } & 11 & 4,2 & & \\
\hline & 10 & 20 & & \multirow{3}{*}{ B } \\
\hline & 4 & 4,2 & Mladeira & \\
\hline & 4 & 4,2 & Gesso & \\
\hline & 1 & 4,2 & \multirow{3}{*}{ Misturado } & \\
\hline \multirow{5}{*}{ ago/16 } & 7 & 4,2 & & $\mathrm{C}$ \\
\hline & 5 & 20 & & \\
\hline & 6 & 20 & Madeira & $\mathrm{B}$ \\
\hline & 11 & 4,2 & Gesso & B \\
\hline & 19 & 4,2 & & Clasce A \\
\hline & 16 & 4,2 & & Classe A \\
\hline set/16 & 1 & 20 & Madeira & $B$ \\
\hline set/10 & 18 & 4,2 & Gesso & B \\
\hline & 8 & 4,2 & Micturado & $C$ \\
\hline & 6 & 4,2 & Mlisturado & C \\
\hline out/16 & 26 & 4,2 & & Classe A \\
\hline & 18 & 4,2 & & \\
\hline & 20 & 4,2 & Gesso & B \\
\hline nov/16 & 25 & 4,2 & & Classe A \\
\hline & 9 & 4,2 & Misturado & $\mathrm{C}$ \\
\hline TOTAL & 363 & 1872,2 & & \\
\hline
\end{tabular}

De acordo com a Figura 1, nos 15 meses de construção foram gerados aproximadamente $1.872,20 \mathrm{~m}^{3} \mathrm{de}$ resíduos, sendo 797,8 $\mathrm{m}$ de resíduos Classe B, destes houve a geração de madeira $\left(482,8 \mathrm{~m}^{3}\right)$ e gesso $(315$ 
$\left.\mathrm{m}^{3}\right), 743,4 \mathrm{~m}^{3}$ de resíduos Classe A e $331 \mathrm{~m}^{3}$ de resíduos misturados (Classe C). Durante o período (setembro de 2015 a novembro de 2016) foram gerados em percentual, $39 \%$ de resíduos Classe A, $43 \%$ Classe B e $18 \%$ Classe C. A pesquisa de Bertol, Raffler e Santos (2013), com 10 obras residenciais na cidade de Curitiba-PR, concluiu que em média são gerados $49 \%$ de resíduos Classe A, Classe B 45\%, Classe C 3\% e Classe D 2\%. A diferença nos percentuais pode ter ocorrido devido a empresa adotar algumas ações que minimizam a geração de resíduos e otimizam a produção, além de que não houve demolições no local, enquanto que no estudo realizado por Bertol, Raffler e Santos ocorreram demolições, o que aumenta a quantidade de resíduos Classe A, já que muitas vezes os restos de demolição não são separados corretamente para daí serem descartados.

Houve geração de resíduos Classe D, porém ainda estava ocorrendo negociações com a transportadora e o local de destinação para que esses resíduos fossem retirados do canteiro de obras, portanto não sendo possível sua quantificação.

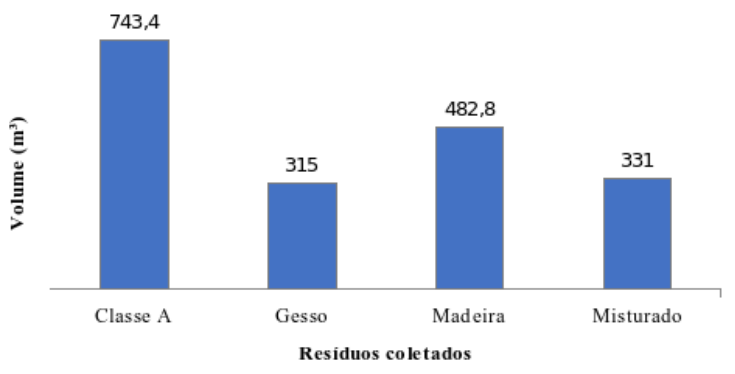

Figura 1: Representação gráfica da geração total dos resíduos Fonte: Autor (2016)

Freitas e Bechtlufft (2010) citam que na fase de "montagem do canteiro" os principais resíduos gerados são concreto e madeira; já na fase de "alvenaria" os principais são concreto, argamassa, blocos cerâmicos, papel e plástico; os autores ressaltam que o volume dos resíduos gerados cai ao passar de uma fase para outra, tendo um aumento na geração de outros resíduos.

$\mathrm{Na}$ obra estudada, o transporte dos resíduos do local de geração até o local destinado ao armazenamento temporário é realizado com carrinhos e elevadores. Há também tubos condutores de resíduos (Figura 2) que encaminham os despejos diretamente de cada pavimento para as caçambas estacionárias devidamente sinalizadas quanto ao tipo de resíduo, evitando desta forma que haja a mistura.

A relação entre o volume total de resíduos gerados e a área construída foi de $0,0662 \mathrm{~m}^{3} / \mathrm{m}^{2}$; valor próximo

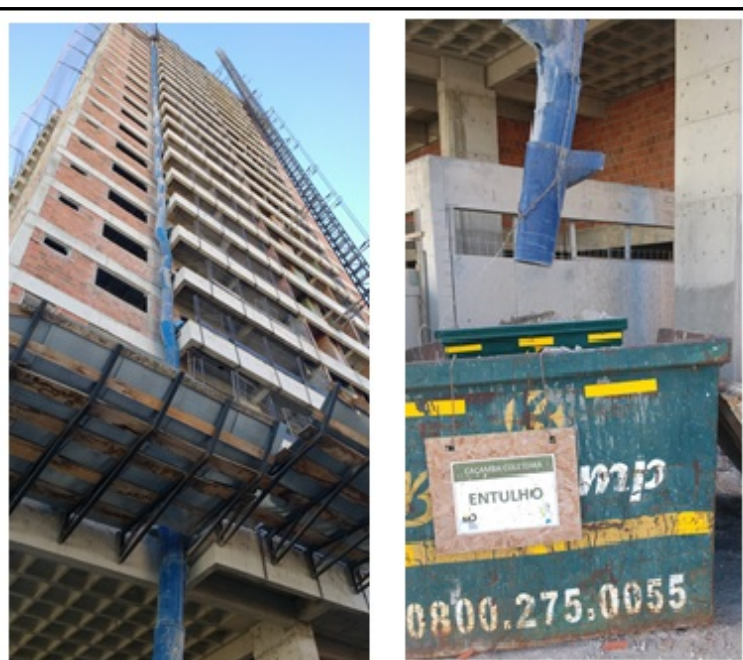

Figura 2: Tubo coletor de resíduos Fonte: Autor (2016)

do encontrado por Bertol, Raffler e Santos (2013) Bertol, Raffler e Santos (2013): $0,0545 \mathrm{~m}^{3} / \mathrm{m}^{2}$ para obras que tem certificação ISO. Já Farias, Fucale e Gusmão (2016) encontraram em Olinda-PE uma taxa de geração de $0,11 \mathrm{~m}^{3} / \mathrm{m}^{2}$.

$\mathrm{Na}$ obra, o acondicionamento é realizado em bombonas, tambores, baias e contêineres, mas algumas bombonas não continham apenas o material para elas especificado, principalmente as que estavam na portaria, pois apresentavam grande diversidade de material misturado. Segundo os responsáveis, essa situação decorre de dois fatores: grande rotatividade de operários e circulação de visitantes, contudo, informaram que esses resíduos são segregados e dispostos adequadamente após coleta interna.

Para o SINDUSCON-CE (2011), a segregação dos resíduos na fonte, além de contribuir com o processo de reciclagem, possibilita a organização e limpeza do local de trabalho, o que resulta na redução do índice de afastamento dos trabalhadores por acidentes provocados pela desordem no canteiro, ou seja, um benefício indireto.

Silva (2011) destaca que dentre as principais dificuldades para o correto gerenciamento dos resíduos está à falta de qualificação dos operários, portanto sendo complicada a aceitação de novas práticas; o autor ressalta que é fundamental as empresas buscarem qualificar melhor seus operários, para que a indústria da construção civil continue crescendo, porém mais sustentável.

Conforme Alves (2015), deveria ser feita uma reorganização no processo construtivo, para que pudesse ser resolvido o problema dos resíduos nos canteiros de 
obras na construção civil; para isso deveriam ser feitas correções partindo dos escritórios de Arquitetura e Engenharia.

$\mathrm{Na}$ tentativa de minimizar o consumo de materiais e evitar desperdícios, a construtora tem um operário envolvido no corte de tijolos no tamanho necessário para acoplar as caixas de passagem (Figura 3).
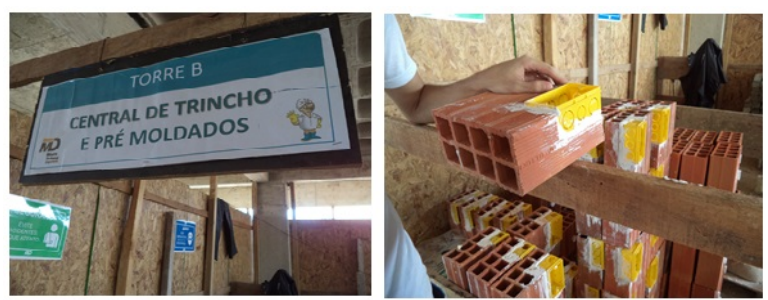

Figura 3: Tijolo com caixa de luz acoplada Fonte: Autor (2016)

Os autores Azevedo, Kiperstok e Moraes (2006) expõem que a prevenção da geração dos resíduos por meio da redução na fonte geradora abrange medidas para a promoção, dentre elas, a adoção de boas práticas operacionais, como o controle e fiscalização da obra, a reciclagem dentro da própria obra, a prevenção de perdas de material, melhores condições de estoque, além da utilização de ferramentas adequadas.

A construtora também possui uma política de integração e treinamento para os seus operários e desenvolve campanhas e premiações. Um bom exemplo é a ação denominada capacete de ouro, onde na última sexta-feira de cada mês é ofertado um café da manhã especial em cada canteiro de obras. Na ocasião, os trabalhadores mais dedicados realizam provas sobre a política de qualidade da empresa e cumprem testes operacionais. O vencedor, por votação popular (gritos, palmas), tem direito a um capacete diferenciado (cor dourada) durante um mês e pode receber como prêmio: batedeira, ventilador, sanduicheira, liquidificador etc., tendo também prioridade na fila do almoço.

Freitas e Bechtlufft (2010) recomendam projetos com alguma recompensa para os trabalhadores sentirem-se motivados e envolvidos no processo de segregação dos resíduos, para que venha a se tornar uma obrigação no dia a dia dessas pessoas.

A obra conta com cartazes nas paredes em todos os pavimentos. São orientações saúde, segurança e meio ambiente. Karpinsk (2009) afirma que a comunicação periódica, por meio de cartazes, murais, chamadas na obra, permite ao empregado pensar de modo ecologicamente correto na sua jornada de trabalho.

Ações semelhantes são recomendadas pela literatura. Segundo o Conselho Regional de Engenharia e
Agronomia do Paraná - CREA-PR (2012), é oportuno que os funcionários sejam treinados e se tornem conhecedores da classificação dos resíduos, pois desta forma executam satisfatoriamente a segregação dos resíduos, também por conta da importância ambiental que essa tarefa representa; os autores relatam que a comunicação visual na obra tem importância fundamental.

Lordêlo, Evangelista e Ferraz (2007) já relatavam ser muito interessante a participação dos operários durante os treinamentos nos canteiros, pois eles se mostravam dispostos a contribuir para o sucesso da segregação, melhoria da limpeza dos seus locais de trabalho, minimizando a geração de resíduos em seus postos de trabalho.

Conforme descrito no Plano de Gerenciamento de Resíduos da Construção Civil (PGRCC) da obra, o programa de educação ambiental deve incluir todos os colaboradores do empreendimento, onde todos estejam conscientes das suas responsabilidades na redução da geração de resíduos, redução do consumo e consciência ambiental. Para tanto, a construtora mensalmente organiza palestras com os seguintes temas: coleta seletiva, conscientização ambiental, consumo racional da água e consumo racional de energia.

O Sinduscon-CE (2011) afirma que os grandes geradores devem elaborar e implementar os PGRCC; estes devem estabelecer os procedimentos necessários para o manejo e destinação ambientalmente adequados dos resíduos. Para Buerger (2015) o PGRCC é uma das ferramentas centrais da gestão dos RCC devendo contemplar tudo o que é previsto pela Política Nacional de Resíduos Sólidos - PNRS; portanto deve ser elaborado de forma a integrar todas as ações necessárias para armazenamento e transporte de resíduos da forma mais segura e sustentável possível, sendo realizada a triagem dos seus resíduos e encaminhando-os para a destinação final mais adequada. A obra conta também com um programa de coleta seletiva (Figuras $4 \mathrm{e} 5$ ).

Observou-se também a geração de outros resíduos como pilhas e baterias e lâmpadas fluorescentes, porém ainda não foram destinados e permanecem no canteiro de obras armazenados em recipientes próprios.

$\mathrm{Na}$ obra estudada foram gerados também resíduos orgânicos (restos de alimentos) e parte desses resíduos estavam sendo coletados por uma pessoa para servir de alimentação para animais e a outra parte dos resíduos orgânicos estava sendo coletados pela coleta municipal, pois estes não tinham volume significativo (segundo os responsáveis pela obra); contudo isto não deveria ocorrer, visto que o empreendimento é classificado como um grande gerador conforme a Lei Municipal $\mathrm{n}^{\mathrm{o}} 10.340 / 2015$, onde no seu art. $1^{\circ}$, inciso I. 


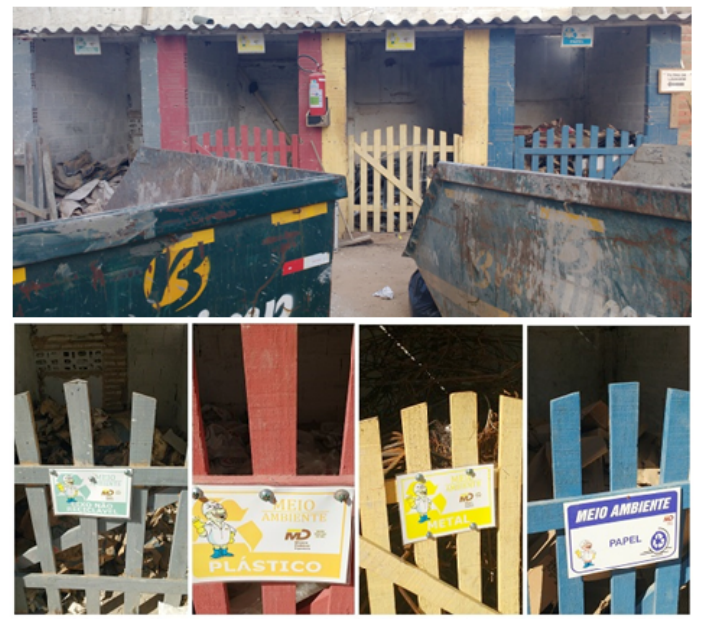

Figura 4: Resíduos nas baias Fonte: Autor (2016)

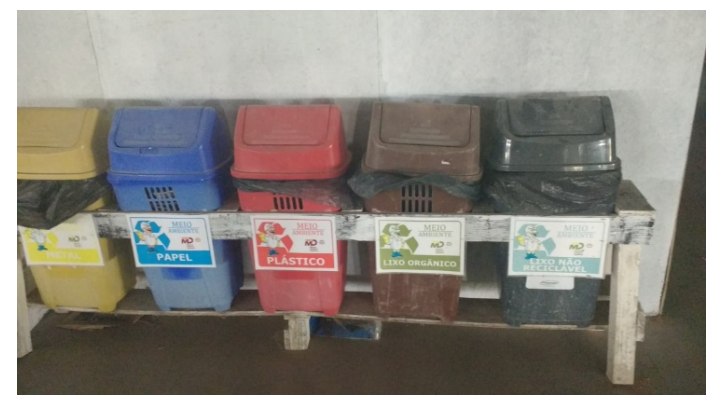

Figura 5: Conjunto de bombonas Fonte: Autor (2016)

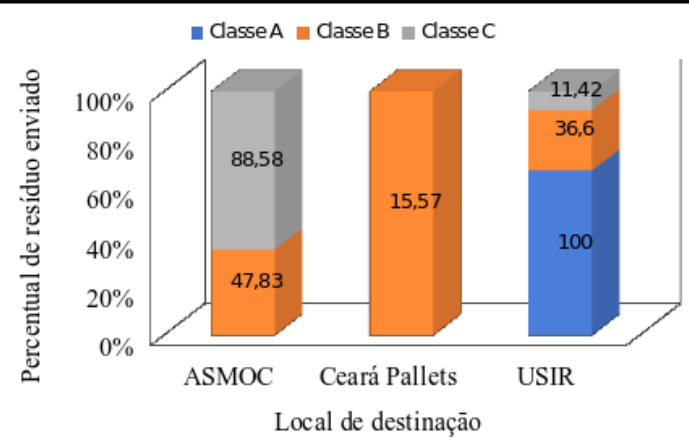

Figura 6: Representação gráfica da destinação dos resíduos Fonte: Autor (2016)

Também houve geração de resíduos de serviços de saúde (gerados no tratamento de ferimentos dos operários), como algumas gases. Foi relatado que não houve nenhum acidente grave desde o início da obra. A coleta desses resíduos é realizada semanalmente ou mensalmente, depende do quantitativo de material acumulado, por uma empresa (clínica) que faz o recolhimento dos resíduos do canteiro de obras e destina juntamente com seus resíduos.

A coleta dos resíduos gerados na obra é realizada por uma transportadora licenciada, com diversas destinações finais (Quadro 2).

Como se observa, uma quantidade significativa de resíduos foi destinada para o ASMOC $\left(674,8 \mathrm{~m}^{3}\right)$ - resíduos das Classes B e C). Para Mesquita (2012), a destinação de RCC para aterros sanitários provoca diversos problemas, sendo o principal deles, o esgotamento acelerado da área do aterro. Quanto ao resíduo de madeira ao ser destinado para a Ceará Pallets, existe a possibilidade de sua transformação em pallets.

Cada saída de resíduos da obra é registrada em MTR (Manifesto de Transporte de Resíduos) e CTR (Controle de Transporte de Resíduos), onde constam as seguintes informações: especificação do resíduo gerado, sua classe, a quantidade, seu volume, a data de saída, e as assinaturas e carimbos dos responsáveis da construtora, transportadora e local de destinação dos resíduos; ressalta-se que também são guardadas as licenças tanto da empresa transportadora como dos locais de destinação final.

Segundo Marque Neto e Schalch (2010), após esgotadas todas as possibilidades de uso dos resíduos, estes devem ser encaminhados para áreas autorizadas ou licenciadas, em concordância com as classes encontradas.

Conforme o Quadro 2 e a Figura 6 os resíduos Classe A foram destinados corretamente, em concor- 
RESÍDUOS DA CONSTRUÇÃO CIVIL: O GERENCIAMENTO EM UMA OBRA RESIDENCIAL DE GRANDE PORTE EM FORTALEZA-CE

Quadro 2: Destinação dos resíduos

\begin{tabular}{|c|c|c|c|c|}
\hline \multirow{2}{*}{ Destino } & \multicolumn{3}{|c|}{ Volume $\left(m^{3}\right)$} \\
\cline { 2 - 5 } & Classe A & Madeira & Gesso & Misturado \\
\hline Aterro Sanitário Metropolitano Oeste de Caucaia - ASMOC & - & 184,2 & 197,4 & 293,2 \\
\hline Ceará Pallets & - & 124,2 & - & - \\
\hline Usina de Reciclagem de Resíduos LTDA - USIR & 743,4 & 174,4 & 117,6 & 37,8 \\
\hline
\end{tabular}

Fonte: Autor (2016)

dância com a literatura onde o CREA-PR (2016) informa que os resíduos pertencentes a esta classe devem ser encaminhados para área de triagem e transbordo, áreas de reciclagem ou aterros da construção civil; o autor salienta que os resíduos da Classe B podem ser comercializados com empresas, cooperativas ou associações de coleta seletiva, ou mesmo serem usados como combustível para fornos e caldeiras; já a destinação dos resíduos das classes $\mathrm{C}$ e $\mathrm{D}$ deve envolver seus fornecedores para que se configure a corresponsabilidade.

Os resíduos Classe B poderiam estar sendo enviados para o ASMOC devido sua separação, já que não estando totalmente separados ou mesmo limpos sua comercialização torna-se mais difícil ou mesmo devido a falta de tecnologias para sua reutilização no local de geração; entretanto o PGRCC da obra orienta a destinação adequada dos resíduos e cita locais adequados para que esses resíduos possam ser enviados.

Vale salientar que parte dos resíduos Classe B, especificamente a madeira, após ser utilizada era colocada em um local no canteiro de obras, para que posteriormente fosse feita a separação dos painéis para sua reutilização na construção da piscina.

Ao serem questionados sobre a destinação dos resíduos Classe B (Papel, Plástico e Metal) os responsáveis pela obra informaram que os mesmos estavam sendo recolhidos por catadores autônomos, que moravam próximo ao canteiro, porém que não serão mais doados para eles, pois a transportadora também irá fazer a coleta desses materiais.

A Secretaria de Articulação Institucional e Cidadania Ambiental (2014) salienta que um grande volume desses materiais, especificamente o RCC, não é destinado para associações ou cooperativas de catadores de materiais recicláveis. Sendo uma ação importante, a coleta seletiva solidária, auxilia na geração de renda dos catadores e na destinação adequada desses resíduos.

Spadotto e Batista (2015) informam que em obras de construção civil o único material geralmente recolhido por associações de catadores é o papel dos sacos de cimento, somente quando já estão separados para a coleta. Considerando que os resíduos misturados (Classe C) eram compostos basicamente por sacos de cimento e de argamassa colante, parte deles caso houvesse a separação, poderia conforme a literatura ser destinado para associações de catadores.

Couto, Naves e Fraga (2016), também classificam sacarias de argamassa, cimento e cal, como resíduos Classe C.

Alguns manuais destacam formas para a destinação correta dos RCC, o SINDUSCON-CE (2011) por exemplo, informa que os sacos de cimento devem retornar à fábrica para utilização como combustível na produção do cimento; sendo assim outra alternativa para a destinação desse resíduo.

Foi informado que são realizadas auditorias internas, com frequência bimestral, e auditorias externas com frequência anual. Ao ser analisado o relatório de auditoria interna da obra estudada, foram obtidas algumas informações, em especial as certificações que a obra: ISO 9001 que certifica o Sistema de Gestão da Qualidade e a ISO 14.001 que trata do Sistema de Gestão Ambiental. Então o Sistema de Gestão Integrada SGI recebeu nota média anual de 8,3 , sua maior nota foi em novembro de 2016 sendo esta 8,8 .

Bertol, Raffler e Santos (2013) afirmam que obras com certificação, têm maior controle no registro de saída de resíduos, devido às exigências das normas, então os dados fornecidos sugerem uma maior confiabilidade.

Nascimento, Cardoso e Secchin (2016) afirmam que são grandes os benefícios da reutilização do RCC; declaram que o reaproveitamento desses resíduos pode ser feito por associações de moradores, gerando emprego, produzindo materiais mais baratos para o próprio setor da construção, como os agregados reciclados.

A madeira após ser utilizada na obra é colocada ao lado dos prédios para que possam ser separados os painéis e posteriormente reutilizá-los na construção da piscina. SINDUSCON-SP (2005) relata que se deve haver atenção especial sobre a possibilidade da reutilização de materiais, o que proporcionaria uma economia, ao dispensar a compra de novos materiais e/ou gastos com a remoção de resíduos.

Para Araújo (2009), a madeira é um material de significativa importância para o canteiro de obras, pois, 
RESÍDUOS DA CONSTRUÇÃO CIVIL: O GERENCIAMENTO EM UMA OBRA RESIDENCIAL DE GRANDE PORTE EM FORTALEZA-CE

tem grande utilização para as fôrmas e construções provisórias. Já Couto, Naves e Fraga (2016) alegam que os resíduos da madeira se tornam um gargalo na gestão dentro do processo produtivo, devido a falta de interesse pela reutilização e reciclagem. Os autores afirmam que isso influencia as construtoras a recorrerem a alternativas como a disposição irregular, a queima pela própria empresa ou ainda a mistura com os demais resíduos.

O manejo e a destinação do RCC são essenciais para que não sejam descartados recursos renováveis, recicláveis ou reutilizáveis, sendo gerado o mínimo possível de resíduos (ARAÚJO, 2009, ZANELATO, 2016).

\section{CONCLUSÃO}

A pesquisa permitiu observar que o gerenciamento dos resíduos gerados no canteiro de obras caracterizase como satisfatório, visto que há um controle interno da quantidade e tipologia do que foi gerado, além de informações sobre o transportador e sua destinação final.

As ações realizadas, dentre elas a preparação do material, palestras, campanhas e premiações, podem ser consideradas importantes formas de se reduzir a geração e melhorar o gerenciamento dos resíduos na obra estudada.

O ponto mais crítico observado foi a existência de resíduos misturados, sendo importante aumentar o controle interno para aprimorar a segregação.

Os resultados dessa pesquisa podem contribuir para a redução da lacuna que há na literatura local pertinente, servindo de base para outras pesquisas.

\section{REFERÊNCIAS}

ABRELPE. Panorama de Resíduos Sólidos no Brasil. 2011. ASSOCIAÇÃO BRASILEIRA DE EMPRESAS DE LIMPEZA PÚBLICA E RESÍDUOS ESPECIAIS. Disponível em: <http://a3p.jbrj.gov.br/pdf/ABRELPE\%20Panorama\% 202001\%20RSU-1.pdf> Acesso em: 17 abr 2016.

ALVES, J. Resíduos da construção civil em obras novas. Interfaces Científicas-Exatas e Tecnológicas, v. 1, n. 1, p. 53-65, 2015.

ARAÚJO, V. M. Práticas recomendadas para a gestão mais sustentável de canteiros de obras. Dissertação (Mestrado em Engenharia) — Escola Politécnica da Universidade de São Paulo, São Paulo, 2009. $228 \mathrm{f}$.

AZEVEDO, G. O. D. d.; KIPERSTOK, A.; MORAES, L. R. S. Resíduos da construção civil em salvador: os caminhos para uma gestão sustentável. Eng. sanit. ambient, v. 11, n. 1, p. 65-72, 2006.
BERTOL, A. C.; RAFFLER, A.; SANTOS, J. P. Análise da correlação entre a geração de resíduos da construção civil e as características das obras. Dissertação (Monografia (Graduação em Engenharia de Produção Civil)) — Universidade Tecnológica Federal do Paraná, Curitiba, 2013. 73 f.

BRASIL. Lei $\mathbf{n}^{\mathbf{0}}$ 12.305, de 02 de agosto de 2010. Altera a Lei $\mathrm{n}^{0}$ 9.605, de 12 de fevereiro de 1998, que institui a Política Nacional de Resíduos Sólidos e dá outras providências. Diário Oficial da União, Brasília, 03 ago. 2010. p. 2. 2010. Disponível em: <http://www.planalto.gov.br/ccivil_03/_ato2007-2010/ 2010/lei/112305.htm>. Acesso em: 17 fev 2018.

Manual para implantação de sistema de gestão de resíduos de construção civil em consórcios públicos. 1. ed. Brasília: Secretaria de Recursos Hídricos e Ambiente Urbano, 2010.

\section{SECRETARIA DE ARTICULAÇÃO}

INSTITUCIONAL E CIDADANIA AMBIENTAL. Plano de gerenciamento de resíduos sólidos. 2014. Disponível em: <http://www.comprasgovernamentais. gov.br/arquivos/cartilhas/cartilha_pgrs_mma.pdf> Acesso em: 12 dez 2016.

BUERGER, A. L. Ferramentas e medidas para a adequação do gerenciamento de resíduos da construção na UFSC - Campus Trindade. Dissertação (Monografia (Graduação em Engenharia Sanitária e Ambiental)) — Universidade Federal de Santa Catarina, Florianópolis, 2015. 200 f.

CONAMA. Resolução no 307, de 05 de julho de 2002. Estabelece diretrizes, critérios e procedimentos para a gestão dos resíduos da construção civil. 2002. CONSELHO NACIONAL DO MEIO AMBIENTE.

Disponível em: <http://www.mma.gov.br/port/conama/ legiabre.cfm?codlegi=307> Acesso em: 25 nov 2016.

Resolução $n^{\circ}$ 448, de 18 de janeiro de 2012. Altera os arts. $2^{\circ}, 4^{\circ}, 5^{\circ}, 6^{\circ}, 8^{\circ}, 9^{\circ}, 10$ e 11 da Resolução no 307 , de 5 de julho de 2002, do Conselho Nacional do Meio Ambiente - CONAMA. 2012. CONSELHO NACIONAL DO MEIO AMBIENTE. Disponível em: <http://www. $\mathrm{mma}$.gov.br/port/conama/legiabre.cfm?codlegi=672> Acesso em: 25 nov 2016.

COUTO, M. S. D. S.; NAVES, A. R. C.; FRAGA, E. A. Resíduos sólidos da construção civil, gargalos e oportunidades: um estudo empírico sobre sua gestão. Cadernos de Educação, Tecnologia e Sociedade, v. 9, n. 2, p. 305-318, 2016. 
RESÍDUOS DA CONSTRUÇÃO CIVIL: O GERENCIAMENTO EM UMA OBRA RESIDENCIAL DE GRANDE PORTE EM FORTALEZA-CE

CREA-PR. Guia para elaboração de projeto de gerenciamento de resíduos da construção civil. Paraná, 2012.

Cunha Júnior, N. B. Cartilha de Gerenciamento de Resíduos Sólidos para a Construção Civil. Minas Gerais, 2006.

DANTAS, T. R. Diagnóstico da situação dos resíduos de construção civil (RCC) no município de Angicos (RN). Dissertação (Monografia (Graduação em Ciência e Tecnologia) ) - Universidade Federal do Semi-Árido - UFERSA, Angicos, 2011. $47 \mathrm{f}$.

FARIAS, A.; FUCALE, S.; GUSMÃO, A. Diagnóstico de gestão de resíduos da construção civil no município de olinda. Revista de Engenharia e Pesquisa Aplicada, v. 2, n. 1, p. 3-12, 2016.

FORTALEZA. Lei n⿳ 10.340, de 28 de abril de 2015. Altera os arts. $1^{\circ}$ ao 33 da Lei 8.408, de 24 de dezembro de 1999, e dá outras providências. Diário Oficial do Município, Poder Executivo, Fortaleza, CE, 08 de maio de 2015, p. 1. 2015. Disponível em: <http://cmfor.virtuaserver.com.br:8080/sapl/sapl_ documentos/norma_juridica/4320_texto_integral $>$ Acesso em: 13 dez 2016.

FREITAS, C. A.; BECHTLUFFT, M. P. Avaliação qualitativa e quantitativa da geração de resíduos da construção civil em obras públicas da empresa a \& s construtora ltda, visando à implementação de um programa de gestão ambiental em pará de minas e região. SYNTHESIS| Revistal Digital FAPAM, v. 2, n. 2, p. 167-180, 2010.

GONÇALVES, R. R. Tratamento dos resíduos sólidos da construção civil no município de Ibirité- MG: resíduos sólidos da construção civil. Dissertação (Mestrado em Sustentabilidade Socioeconômica e Ambiental) - Universidade Federal de Ouro Preto, Minas Gerais, 2011. 96 f.

IPEA. Diagnóstico dos resíduos sólidos da construção civil. 1. ed. Brasília: Secretaria de Assuntos Estratégicos da Presidência da República SAE/PR, 2012.

KARPINSK, L. A. Gestão diferenciada de resíduos da construção civil: uma abordagem ambiental. 1. ed. Porto Alegre: Edipucrs, 2009.

LORDÊLO, P. M.; EVANGELISTA, P. P. A.; FERRAZ, T. G. A. Programa de gestão de resíduos em canteiros de obras: método, implantação e resultados. In: ENCONTRO NACIONAL
SOBRE EDIFICAÇÕES E COMUNIDADES SUSTENTÁVEIS. Bahia: Anais, 2007. v. 4, p. 1037-1046.

MARCONI, M. A.; LAKATOS, E. M. Fundamentos de metodologia científica. 7. ed. São Paulo: Atlas, 2010 .

Marque Neto, J. C.; SCHALCH, V. Gestão dos resíduos de construção e demolição: estudo da situação no município de são carlos-sp, brasil. Revista Engenharia Civil, v. 1, n. 36, p. 41-50, 2010.

MESQUITA, A. S. G. Análise da geração de resíduos sólidos da construção civil em teresina, piauí. Holos, v. 2 , n. 28 , p. $58-65,2012$

NASCIMENTO, F. M.; CARDOSO, L. C.; SECCHIN, L. F. Descarte de resíduos sólidos da construção civil-um panorama no município de lajinha-mg. REMAS-Revista Educação, Meio Ambiente e Saúde, v. 6, n. 4, p. 36-38, 2016.

PINTO, T. P. Metodologia para a gestão diferenciada de resíduos sólidos da construção urbana. Tese (Doutorado em Engenharia de Construção Civil e Urbana) - Escola Politécnica, Universidade de São Paulo, São Paulo, 1999. 189 f.

SEVERINO, A. J. Metodologia do trabalho científico. 23. ed. São Paulo: Cortez, 2007.

SILVA, A. F. F. Gerenciamento de resíduos da construção civil de acordo com a Resolução CONAMA no 307/02 - Estudo de caso para um conjunto de obras de pequeno porte. Dissertação (Mestrado em Saneamento, Meio Ambiente e Recursos Hídricos) - Universidade Federal de Minas Gerais, Belo Horizonte, 2007. $102 \mathrm{f}$.

SILVA, E. L.; MENEZES, E. M. A pesquisa e suas classificações. In: Metodologia da pesquisa e elaboração de dissertação. 4. ed. Florianópolis: Universidade Federal de Santa Catarina: Silva, E. L. and Menezes, E. M., 2005.

SILVA, L. M. Gestão de resíduos da construção civil: dificuldades para implementação do plano integrado de gestão de resíduos no município de São Leopoldo. Dissertação (Graduação em Engenharia Civil) - Universidade Federal do Rio Grande do Sul, Porto Alegre, 2011. $86 \mathrm{f}$.

SINDUSCON-CE. Manual sobre os resíduos sólidos da construção civil. Ceará, 2011. 
SINDUSCON-SP. Gestão ambiental de resíduos da construção civil: a experiência do SINDUSCON-SP.

São Paulo, 2005. 48 p.

Resíduos da construção civil e o

estado de São Paulo. 2012. Disponível em:

$<$ http://www.ambiente.sp.gov.br/cpla/files/2012/09/

residuos_construcao_civil_sp.pdf> Acesso em: 26

nov 2016.

SPADOTTO, A.; BATISTA, G. R. Destinação dos

resíduos da construção civil - Xanxerê, Santa

Catarina. Santa Catarina, 2015.

VALPORTO, M. S.; AZEVEDO, P. S. A. P. S.;

AZEVEDO, P. S. Gestão do design na identificação

dos fatores de impactos ambientais da construção civil.

Estudos em Design, v. 24, n. 1, p. 124-151, 2016.

ZANELATO, V. K. Estudo de caso sobre gestão de resíduos sólidos da construção civil em obra na cidade de Florianópolis. Dissertação (Monografia (Graduação em Engenharia Civil)) - Universidade Federal de Santa Catarina, Florianópolis, 2016. 79 f. 